\title{
Performance analysis of manganese ferrite nanoparticles for the removal of zinc from synthetic wastewater
}

\author{
J. Jeyanthi ${ }^{*}$, K.R. Aswin Sidhaarth ${ }^{1}$ and R. Jayalakshmi ${ }^{2}$ \\ ${ }^{1}$ Department of Civil Engineering, Government College of Technology Coimbatore - 641 013, India \\ ${ }^{2}$ Department of Civil Engineering, Vel Tech University, Chennai - 600 062, India \\ *Email: gctjeyanthi@gmail.com
}

The presence of heavy metals in wastewater and surface water is becoming a severe environmental and public health problem. They accumulate in living tissues throughout the food chain, which has humans at its top. These toxic metals can cause accumulative poisoning, cancer, and brain damage when found above the tolerance levels. Zinc compounds are very toxic to humans.

In this study, manganese ferrite nanoparticles have been synthesized using co-precipitation method and applied for the selective removal and recovery of heavy metals from synthetic wastewater. The FEG-SEM, TEM analysis and FTIR analysis were employed to determine the surface morphology, size of the nanoparticle and the presence of functional groups in the sample. Manganese ferrite nanoparticle as a novel adsorbent is expected to offer an attractive option for the removal of heavy metals by considering its simple synthesizing method, high surface area, and magnetic properties.

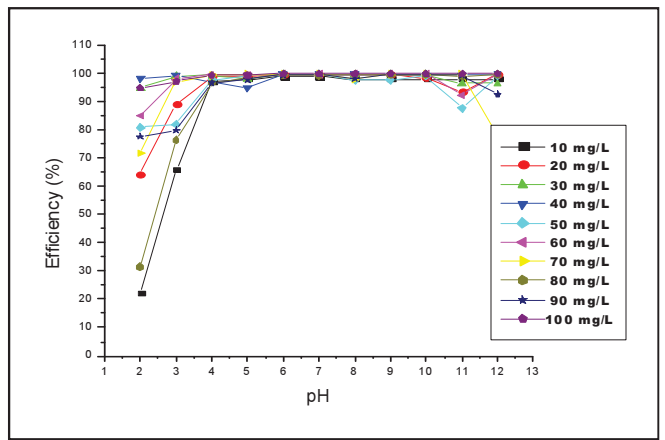

Figure 1: Effect of hydrogen ion concentration and concentration of zinc (a) contact time 30 minutes, agitation speed: $150 \mathrm{rpm}$ temperature $30{ }^{\circ} \mathrm{C}$ )

The objective of the present work is to investigate the potential feasibility and field applicability of manganese ferrite nanoparticles for the adsorption of zinc from the synthetic solution.

The adsorption characteristics and Zinc removal efficiency of the adsorbent have been determined by investigating the influence of operating variables such as contact time, dosage, $\mathrm{pH}$, concentration of zinc and agitation speed (Figure 1 and Figure 2). The isotherm and kinetic studies suggest that the process follows Langmuir, Tempkin Pseudo second kinetics. Column studies were also performed to test the ground efficiency of manganese ferrite nanoparticles by varying the depth and the results were subjected to Thomson and Yoon Nelson modeling.

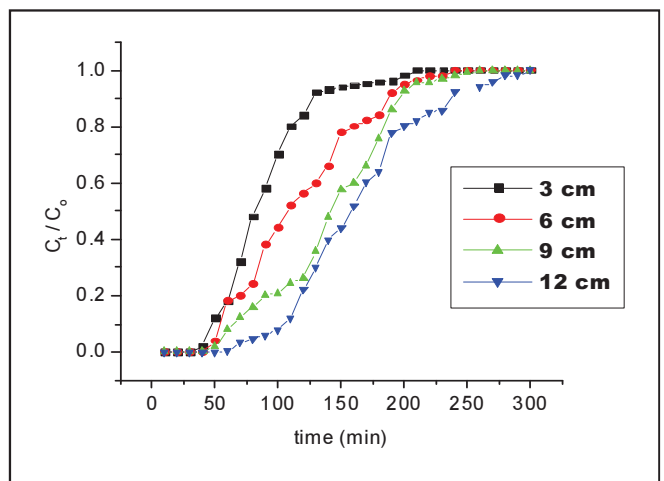

Figure 2: Effect of bed height on the breakthrough curve (Conditions: $\mathrm{pH} 5.19$; adsorbate concentration $50 \mathrm{mg} / \mathrm{L}$; flow rate $5 \mathrm{~mL} / \mathrm{min}$ )

\section{References}

1. Erhan Demirbasa et.al Water SA vol 30 533-539, October 2004.

2. Jing Hu et.al J. Environ. Eng. Vol 132, 709-715, November 2005. 